\title{
Traumatic Spinal Cord Injuries in Gold Miners in Mali: Preliminary Study on 76 Cases
}

\section{Oumar Coulibaly ${ }^{1 *}$, Mahamadou Dama ${ }^{1}$, Oumar Diallo ${ }^{1}$, Daouda Sissoko', Boubacar Sogoba1, Singuepiré Alpha1, Youssouf Sogoba², Drissa Kanikomo²}

\author{
${ }^{1}$ Hôpital du Mali, Bamako, Mali \\ ${ }^{2}$ Hôpital Gabriel Touré, University of Sciences, Technics and Technologies of Bamako (USTTB), Bamako, Mali \\ Email: *coulibalynch1@gmail.com
}

How to cite this paper: Coulibaly, O., Dama, M., Diallo, O., Sissoko, D., Sogoba, B., Alpha, S., Sogoba, Y. and Kanikomo, D. (2019) Traumatic Spinal Cord Injuries in Gold Miners in Mali: Preliminary Study on 76 Cases. World Journal of Neuroscience, 9, 208-215

https://doi.org/10.4236/wjns.2019.93014

Received: February 4, 2019

Accepted: August 19, 2019

Published: August 22, 2019

Copyright $\odot 2019$ by author(s) and Scientific Research Publishing Inc. This work is licensed under the Creative Commons Attribution International License (CC BY 4.0).

http://creativecommons.org/licenses/by/4.0/

\begin{abstract}
Introduction: Gold panning is the research and artisanal exploitation of gold in the auriferous areas (rivers or others). Traumatisms arising from these activities are due to severe spinal cord injury and generally affect young people in full activity. They constitute a real social handicap in Mali and even in Africa. The aim of our study is to share our expertise in the management of these vertebro-medullary traumas in these miners who currently escape to all controls in Mali. Material and Methods: From 2013 to 2016, 76 Traumatic Spine Cord Injuries (TSCI) were treated in the department of Neurosurgery of "Hôpital du Mali". There were 73 males (96.05\%) versus 03 Females (3.95\%), aged between 21 - 43 years old. Results: All of our patients were admitted with deficit differing from paraparesis to tetraplegia. According to Frankel scale, we found 59 patients with complete deficits (A grade, 77.63\%), and incomplete deficits in 17 cases (12 grade $B, 04$ grade $C, 01$ grade $D)$. The $\mathrm{X}$-ray standard radiographies were done in 24 cases (31.58\%) from which 02 patients had been operated with these data. CT scan centered on the injured spinal segment was performed in 74 cases (97.37\%). The lumbar spine was affected in 39 cases, followed by thoracolumbar junction in 19 cases and thoracic spine in 16 cases. The cervical spine was only interested in two cases. Fractures dislocations are the most frequently lesions encountered in our series. The surgical approach was performed in 74 patients and 02 patients received conservative treatment. Conclusion: Traumatic Spinal Cord Injuries (TSCI) among miners are a real disaster in Mali and continue to plague thousands of families or increase the number of disabled people in our society. It is the only work, where the person concerned is making of his own grave. And according to witnesses, several miners remained at the bottom of the wells. Their prevention must first involve users by raising the awareness of local residents and traditional therapists, but also the country that must
\end{abstract}


participate in regional development and ensure strict enforcement of regulatory measures. Our structure must have enough resources to acquire and treat these patients at any time.

\section{Keywords}

Spinal Cord Injury, Gold, Mali

\section{Introduction}

Gold panning is the research and artisanal exploitation of gold in the auriferous areas (rivers, or others). Traumatisms arising from these activities are generally due to severe spinal cord injury and often result in death in short-term or irreversible motor and sensory deficits in medium to long term. Generally, Road Traffic Accidents (RTAs) seem to be the major cause of TSCI worldwide, mainly in industrial countries. But in Mali, from 2000 to nowdays, gold panning occupied the second place after these RTAs in Mali.

They generally affect young people in full activity, aspiring for a better future. So, they constitute a real social handicap in Mali and even in Africa. These TSCI should be considered as a neurosurgical emergency and a closed collaboration between neurosurgeon, neuroradiologist, neuroanesthesist and emergency praticians are so needed.

Our present study concerns a series of 76 gold miners treated in the department of neurosurgery of "Hôpital du Mali" from 2013 to 2016. During this same period, we recorded a total of 146 cases of TSCI from any associated etiology, from which 97 patients come from artisanal gold panning sites. So, these traumatic spinal cord injured patients account $52.05 \%$ of all traumatic spinal cord cared in our department.

The aim of our study is to share our expertise in the management of these traumatic spinal cord injuries in these miners who currently escape to all controls in Mali.

\section{Material and Methods}

From 2013 to 2016, we retrospectively enrolled 76 patients with TSCI after mining trauma and treated in our department of Neurosurgery in "Hôpital of Mali". Most of the patients were between 21 - 43 years old (78.95\%). The average age of our patients was 31 years with extremes ranging from 14 to 62 years. There were 73 males (96.05\%) versus 03 Females (3.95\%). All of our patients were admitted with deficit differing from paraparesis to tetraplegia (Figure 2).

The X-ray standard radio graphies were done in 24 cases (31.58\%) from which 02 patients had been operated with these data. CT scan centered on the injured spinal segment was performed in 74 cases (97.37\%). The lumbar spine was affected in 39 cases, followed by thoracolumbar junction in 19 cases and thoracic spine in 16 cases. The cervical spine was only interested in two cases. Elsewhere, 
21 out 97 traumatic gold miners admitted in our emergency signed discharge, sometimes after CT scan. All our patients had been surgically managed except two who underwent conservative treatment.

\section{Results}

Men, especially those aged 21 to 43 years old, remain the most affected patients in our study with $96.05 \%$. This high rate can be explained by the role played by men in our society as a family economic engine, but also by the fact that gold mining requires a work of sustained strength (Figure 1). Direct impaction was the most common mechanism and mine rock fall was the most frequent cause (fall of a rock or a spinal impact helicopter) in 74 cases, followed by 02 cases of assault respectively by knife and by shotguns. Unemployed youth were the most affected, followed by farmers and housewives.

The average time from injury to medical care was 05 days with extremes ranging from 2 - 60 days.

All our patients had total or partial neurological deficits in $100 \%$ of cases with sphincter disorders in $85 \%$ and spinal syndrome in $75 \%$ (Figure 2). According to Frankel scale, we found 59 patients with complete deficits (A grade, 77.63\%), and incomplete deficits in 17 cases (12 grade $\mathrm{B}, 04$ grade $\mathrm{C}, 01$ grade $\mathrm{D}$ ).

CT scan was the main diagnosis tool used in our study (74 cases), followed by $\mathrm{X}$-ray in 24 cases. Spinal cord MRI was only performed in paraplegic with a white weapon. Fractures dislocations are the most frequently lesions encountered in our series and the lumbar region was most affected (39 cases) followed by the thoracolumbar junction (19 cases). Some cases are illustrated in Figure 3 and Figure 4.

The surgical approach was performed in 74 patients with hard reduction and osteosynthesis in almost cases, and a simple laminectomy in 02 cases. Two of our patients received conservative treatment: one screened with shotguns with

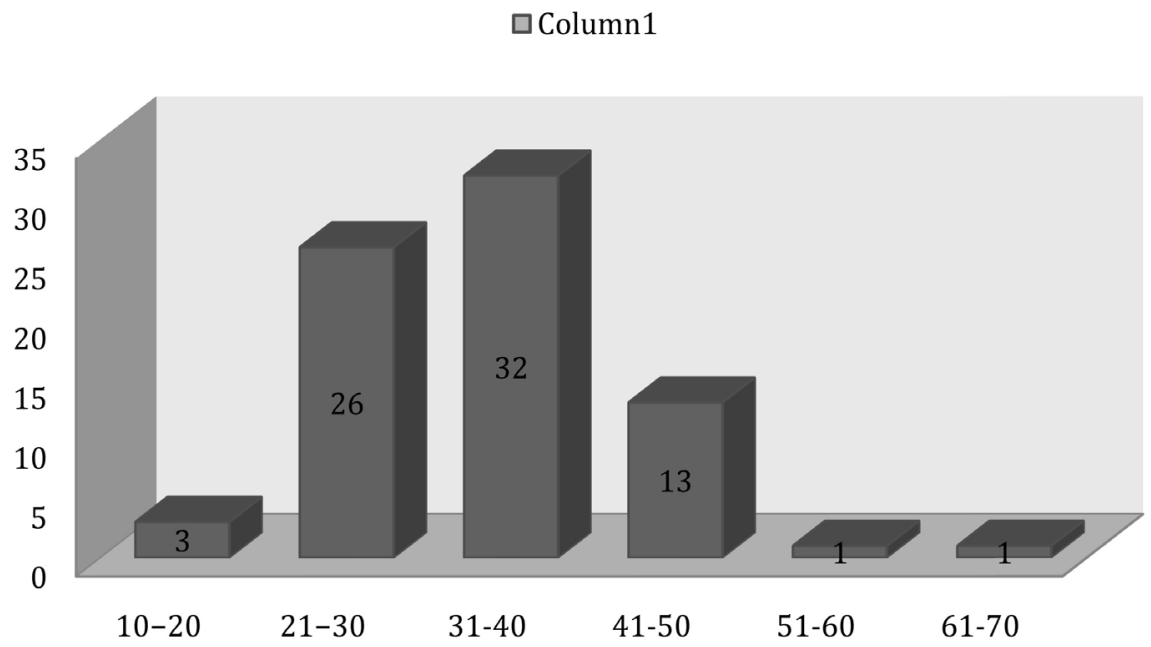

Figure 1. Age distribution of gold-workers admitted to the service. 


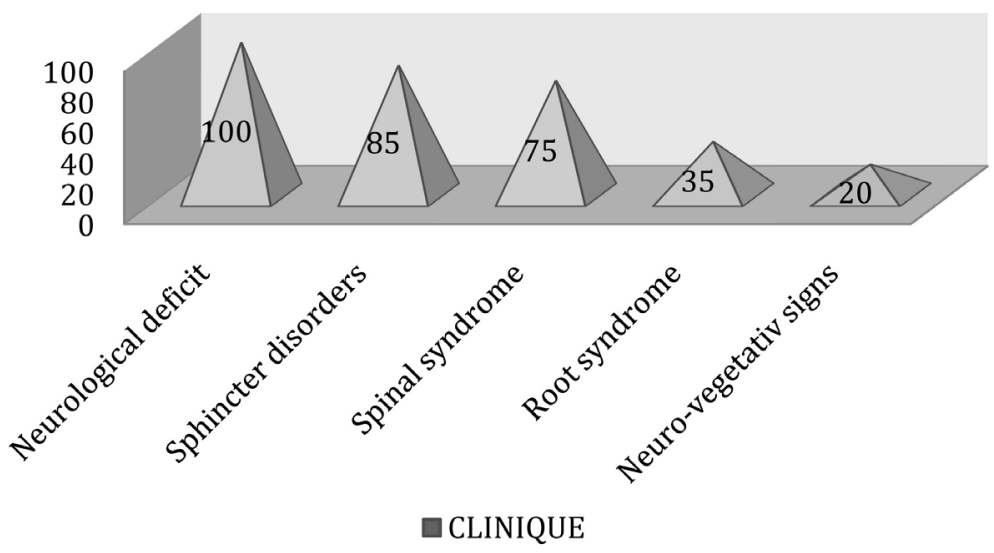

Figure 2. The main clinical signs encountered in gold diggers.

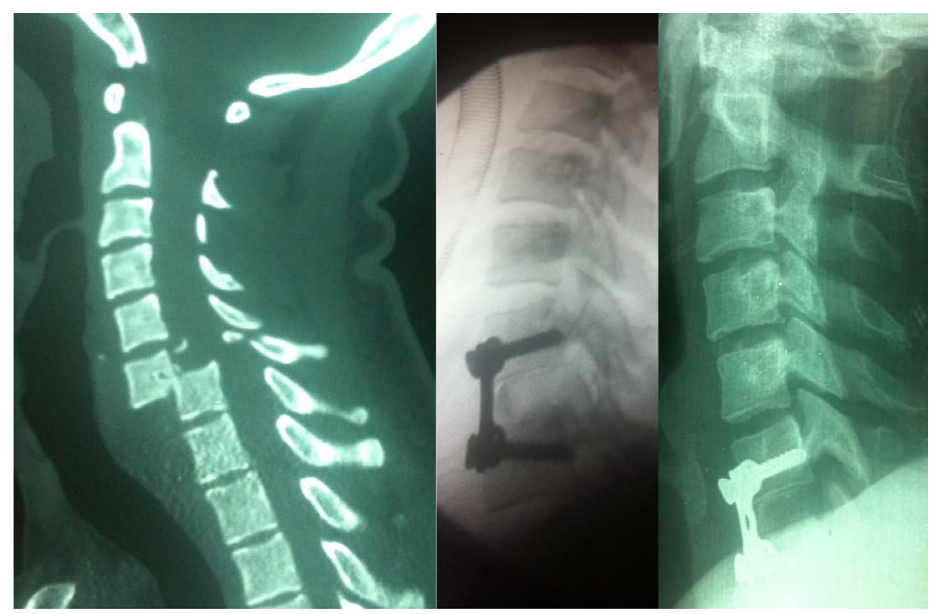

Figure 3. Preoperative CT scan and radiographic imaging C6/C7 dislocation in a 26 years old miner.

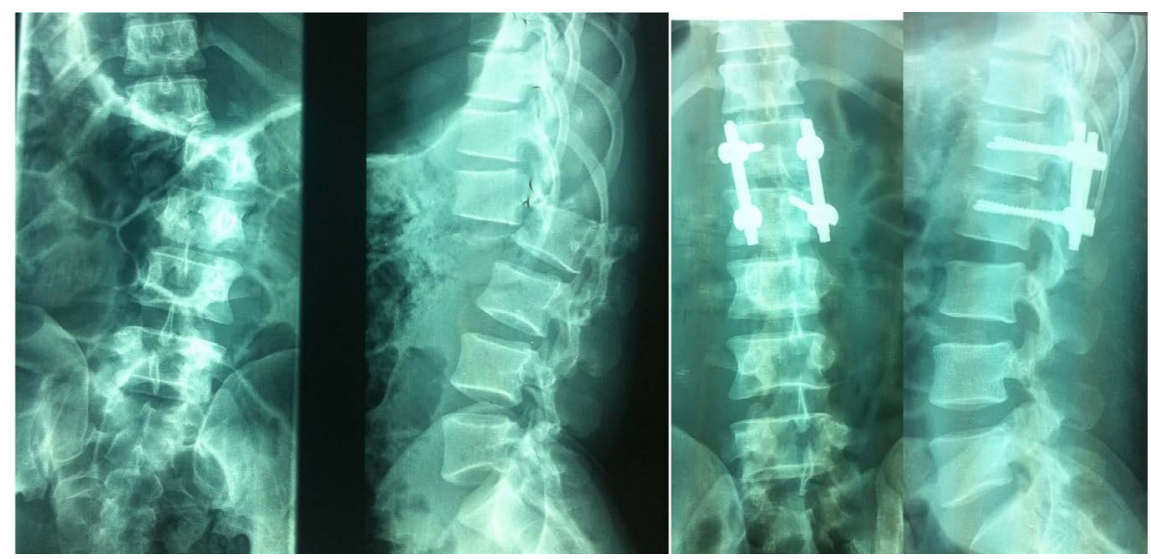

Figure 4. Pre and post radiographic imaging in a 38 years old man (important L1/L2 dislocation).

no major neurological signs and the second, the luckiest victim of a landslide of approximately 05 meters with a transient paraparesis at $4 / 5$ and without scanno graphic lesions. Unfortunately and lack of means, this later patient did not bene- 
fit a lumbar MRI.

Immediately after surgery, one of our patients presented transient dysphagia which regressed under corticosteroid therapy. We noted 03 cases of infections (delayed healing in 02 cases and 01 case of infection of the site of the iliac graft) and 08 cases of sacral and gluteal ulcers.

Table 1 summarizes the average and long-term postoperative outcome of our patients with an average follow-up of 6 months. At the end of follow up period extended from 3 months to 12 months, only 12 patients recovered (10 totally from partial deficit group Frankel scale B, C, D and 02 partially from total deficit group Frankel scale A), 40 patients remained stationary (37 Frankel grade A, 02 Frankel grade B and 01 Frankel grade C); 01 patients worsened and 07 cases went out against medical advice due to lack of means (see Table 1).

We lost 16 patients, death generally due to the lack of nursing and means often during or after hospital stay. This duration comprised between ten days to eleven months.

\section{Discussion}

Traumatic spinal cord injuries (TSCI) are spine trauma with neurological impairment. Those related to the artisanal exploitation of gold (traditional or mechanized gold panning) constitute with RTAs the most disabling causes for young people under 40 years old in Mali. In our study, we recorded in our emergency department $66.44 \%$ (97 cases) of patients coming from mining sites versus $32.19 \%$ ( 47 cases) caused by motor vehicle accidents.

For economic constraints and the desire to have a better future, most of these young try this adventure through mining sites. There are usually unemployed (graduates or farmers) dispersed on these different places and noted respectively in $51 \%$ and $45 \%$. They operated as workers, subcontractors, operators or all kinds of small business activities makers. Although this activity had existed in Mali since the $7^{\text {th }}$ century, but it had had a renewed interest since the 1980 's following the effects of the drought [1] [2].

The first three administrative regions of Mali (Kayes, Koulikoro, Sikasso), remain the most affected mining sites, with respectively $60 \%, 5 \%$ and $35 \%$. Four men from different countries were also included in our series. This diversity

Table 1. Six months post operativ follow up in our patients.

\begin{tabular}{ccccccc}
\hline $\begin{array}{c}\text { Evolution } \\
\text { Frankel }\end{array}$ & Death & Recovery & $\begin{array}{c}\text { Stationary } \\
\text { clinical state }\end{array}$ & Aggravation & $\begin{array}{c}\text { Exit without } \\
\text { medicaladvice }\end{array}$ & TOTAL \\
\hline A & 15 & 02 & 37 & 0 & 05 & 59 \\
B & 01 & 06 & 02 & 01 & 02 & 12 \\
C & 0 & 03 & 01 & 0 & 0 & 04 \\
D & 0 & 01 & 0 & 0 & 0 & 01 \\
E & 0 & 0 & 0 & 0 & 0 & 0 \\
TOTAL & 16 & 12 & 40 & 01 & 07 & 76 \\
\hline
\end{tabular}


shows that this ancestral practice remains a sub-regional scourge in West Africa. In the field, our team met young people coming from different horizons of Mali, added more than eight nationalities on a single site in the first region. On this site, the men were preponderant and worked very hard to seek for this untold treasure (Figure 5).

These spinal cord injured patients from mining sites are generally very serious cases regarding the severity of the trauma (direct impaction of rock falls or dropping filled small containers) on the spine on flexion. About the 59 Frankel A patients, only 02 cases recovered partially. Maybe, those cases were incomplete lesions misdiagnosed at the initial examination. For precautions, the authors prefer to explain to these patients, there is no chance of recovery or very little if complete lesions. The mechanism of these isolated recoveries is not clear in our mind.

Bedbrook [3] stated, the neurological status occurs at the time of the accident, in other words, prognosis is determined from the beginning.

For these reasons, one must not decide whether a lesion is complete or incomplete before 3 weeks in the case of patients with paraplegia and 5 weeks in those with tetraplegia [4].

In his experimental studies, Guha [5] showed that surgical decompression procedures made within the first 4 hours following the injury may have some improvement, but even so, the severity of the trauma is the main determinant for the prognosis. Ersmark [6] stated that there is no correlation between the method of treatment and the outcome. According to Bedbrook [7], improvement in the neurological status is the result of long term sensorial stimulation and isometric muscle exercises. The majority of our patients had been admitted with paraplegia or tetraplegia, several days or weeks after their trauma. Their chance of recovery was very small.

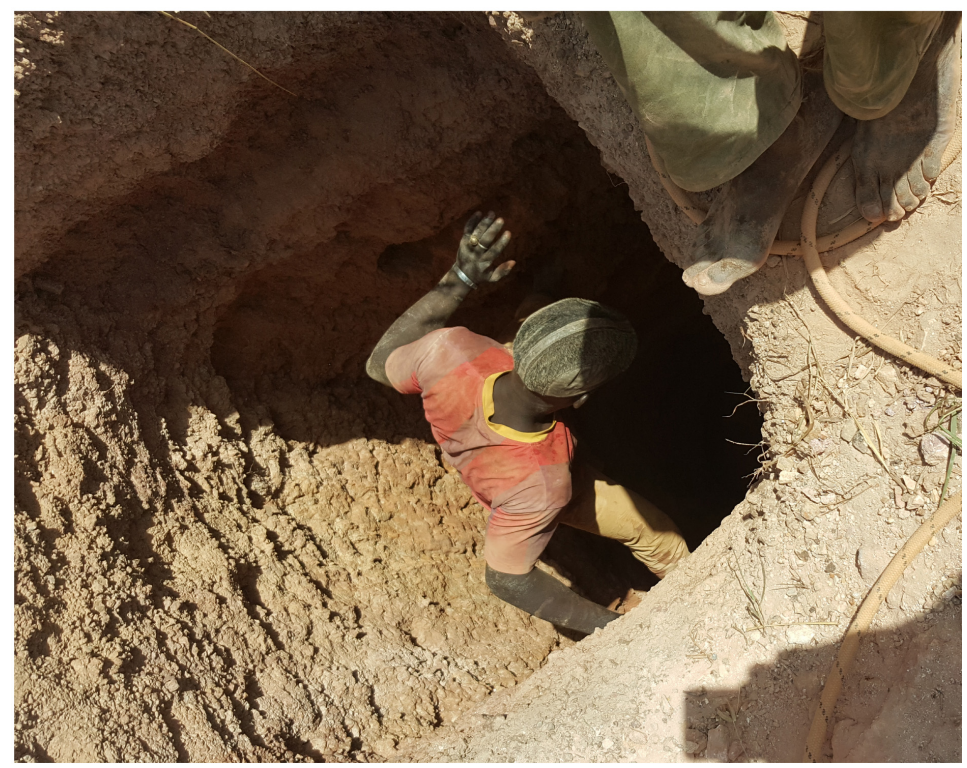

Figure 5. Photograph of a miner descending into the well. 
Elsewhere, traditional mining sites had been invaded by people of extremely heterogeneous social and ethnic origin and remain a favorable environment to the popularization of juvenile delinquency in all these forms (alcohol abuse, prostitution, fraud, banditry, trafficking in narcotics, criminality). These constations had been mentioned by other authors [1] [2].

The high number of cases had been recorded between December and May. However, $5 \%-10 \%$ of the artisanal mines remain active even during the rainy season [2].

The delay in care is due to the fact that many of these victims first pass to the traditional therapists before ending up in the hospital.

Now, with no financial support, most families signed discharge after medical explanations, especially those with permanent disability. This situation had been favored by the distribution of neurosurgeons on our country, most concentered in capital district. This is why we had had 28 signatures in our series.

Elsewhere, infectious diseases like malaria, gonorrhea, AIDS and dermatological diseases were common in miners. We found 02 HIV infection and 03 dermatologic infections on the tested patients. During the hospitalization, most of our patients were treated for malaria.

Despite the regulatory texts adopted in Mali [8], the artisanal exploitation of gold continues to create conflicts between farmers and village occupants, and remains a social problem that firstly hurts Malian or even African youth, the environment through uncontrolled deforestation and the use of chemicals products.

\section{Conclusion}

Traumatic Spinal Cord Injuries (TSCI) among miners are a real disaster in Mali and continue to plague thousands of families or increase the number of disabled people in our society. It is the only work, where the person concerned is making of his own grave. And according to witnesses, several miners remained at the bottom of the wells. Their prevention must first involve users by raising the awareness of local residents and traditional therapists, but also the country that must participate in regional development and ensure strict enforcement of regulatory measures. Our structure must have enough resources to acquire and treat these patients at any time.

\section{Conflicts of Interest}

The authors declare no conflicts of interest regarding the publication of this paper.

\section{References}

[1] Grätz, T. (2013) Gold Mining Camps and Mining Communities in West Africa. ZMO Working Papers 10.

[2] Keita, S. (2001) Study on Artisanal and Small-Scale Mining in Mali. Mining, Miner- 
als and Sustainable Development (MMSD), Working Paper 80, International Institute for Environment and Development (IIED), London.

[3] Bedbrook, G.M. and Sakae, T. (1982) A Review of Cervical Spine Injuries with Neurological Dysfunction. Paraplegia, 20, 321-333.

https://doi.org/10.1038/sc.1982.62

[4] Michaelis, L.S. (1976) Prognosis of Spinal Cord Injury. In: Vinken, P.J. and Bruyn, G.W., Eds., Handbook of Clinical Neurology, Vol. 26, North Holland Publishing Company, Amsterdam, 307-312.

[5] Guha, A., Tator, C.H., Endrenyi, L. and Piper, I. (1987) Depression of the Spinal Cord Improves Recovery after Acute Experimental Spinal Cord Compression Injury. Paraplegia, 25, 324-339. https://doi.org/10.1038/sc.1987.61

[6] Ersmark, H., Dalen, N. and Kalen, R. (1990) Cervical Spine Injuries: A Follow-Up of 332 Patients. Paraplegia, 28, 25-40. https://doi.org/10.1038/sc.1990.4

[7] Bedbrook, G.M. (1979) Spinal Injuries with Tetraplegia and Paraplegia. The Journal of Bone and Joint Surgery. British Volume, 61, 267-284.

https://doi.org/10.1302/0301-620X.61B3.225332

[8] Ordonnance $\mathrm{N}^{\circ}$ 99-032 P-RM du 19/8/99, portant Code Minier au Mali; Décrets $\mathrm{N}^{\circ}$ 99-255/P-RM du 15 Septembre 1999, fixant les modalités d'application du Code Minier en République du Mali. 